\title{
Leitura em foco: estratégias de produção e consumo de produtos editoriais no Brasil
}

Andréa Antonacci

Doutora em Comunicação e Práticas de Consumo pela Escola Superior de Propaganda e Marketing de São Paulo e jornalista pela Universidade Estadual Paulista. Também é docente nos cursos de Jornalismo e Produção Editorial da Universidade Anhembi Morumbi.

E-mail: aantonacci71@gmail.com

Resumo: Dos produtos comunicacionais, o livro e a leitura são os que historicamente acabam por merecer menor atenção de investigadores da área. Esse cenário tem mudado com o já consolidado grupo de pesquisa da Intercom (Sociedade Brasileira de Estudos Interdisciplinares da Comunicação), que desde 1994 é destinado aos estudos das produções editoriais e sua recepção. A obra aqui resenhada, Edição: agentes e objetos, organizada por Ana Cláudia Gruszynski, Bruno Guimarães Martins e Márcio Souza Gonçalves, é resultado de investigações capitaneadas por profissionais desse time de pesquisadores, propondo investigações acuradas e reflexões profícuas sobre o universo da leitura e do leitor no Brasil.

Palavras-chave: comunicação; educação; estratégias de produção de livros; práticas de consumo de livros; Brasil.
Abstract: Of communicational products, books and reading are those that have historically received less attention from researchers in the field. This scenario has changed with the already consolidated research group of Intercom (Brazilian Society of Interdisciplinary Studies in Communication), which has studied editorial productions and their reception since 1994. The work we reviewed, Edição: agentes e objetos, organized by Ana Cláudia Gruszynski, Bruno Guimarães Martins and Márcio Souza Gonçalves, is the result of investigations led by professionals from this team of researchers, proposing accurate investigations and fruitful reflections on the universe of the reading and the reader in Brazil.

Keywords: communication; education; book production strategies; book consumption practices; Brazil. 
Assinado por Isabel Travancas, o primeiro capítulo da obra Edição: agentes $e$ objetos $^{1}$ ressalta em suas considerações finais um dos elementos inquietantes para quem investiga o universo literário no Brasil: a pequena participação do livro, do mercado editorial e dos leitores como objeto de estudo nas pesquisas comunicacionais. Exceções ficam por conta de estudos geralmente concentrados na produção de raros cursos dedicados à elaboração de livros no Brasil, como bem observa Travancas. Exceção igualmente feita e destacada no prefácio da obra, assinado por Aníbal Bragança, professor aposentado da Universidade Federal Fluminense (Niterói, Rio de Janeiro) e pesquisador dos estudos do livro e da leitura, bem como da história editorial brasileira e das políticas públicas para o setor no país. Bragança cita a atuação do grupo de pesquisadores de Produção Editorial nos congressos realizados pela Intercom (Sociedade Brasileira de Estudos Interdisciplinares da Comunicação), da qual a obra aqui resenhada é fruto.

Sendo uma área multidisciplinar, sua formação agregou pesquisas de segmentos do conhecimento comunicacional e de suas interfaces, como a História, o Design, a Biblioteconomia, a Educação, as Letras, dentre outras, transformando-se em espaço de encontros e trocas entre aqueles que se dedicam aos estudos do livro, das editoras e das leituras².

Assim, a relevância desse livro e dos artigos nele presentes já se faz preponderante para o campo da Comunicação e Educacção. São dezessete textos, distribuídos em quatro grandes temas: leituras e leitores; materialidades e produção de sentidos; editoras e edição; aproximações históricas. $\mathrm{Na}$ primeira parte, Leitura e construção de si, Travancas reflete sobre a relação entre literatura e receptor, pontuando sobre o papel do leitor em processos de subjetivação e apropriação.

Neste sentido, a recepção põe a comunicação entre os dois lados da relação: texto e leitor. De um lado, o efeito condicionado pelo texto e de outro a recepção, condicionada pelo leitor. Surgem, portanto, dois horizontes: o interno e o literário. O primeiro construído pela obra, e o outro trazido pelo leitor de uma determinada sociedade em um momento específico ${ }^{3}$.

Um dos pontos altos do artigo são as reflexões empreendidas a partir de duas pesquisas com leitores. A primeira foi conduzida na França pela antropóloga Michèle Petit em 2008, reunindo 90 adolescentes daquele país, numa investigação composta por entrevistas abertas e profundas. Já a segunda pesquisa foi realizada por Roberta Manuela Andrade e Erotildes Silva em 2011, junto a um grupo de mulheres leitoras de Fortaleza (Ceará). Travancas utiliza ambas para abordar a relação entre literatura e lazer; o papel transformador do romance; bem como os espaços físicos e virtuais de significação e de consumo, como bancas e sebos, assim como comunidades leitoras na internet.

[...] a leitura é uma prática cultural que sofreu e sofre inúmeras transformações. Da leitura intensiva e em voz alta na Idade Média à leitura extensiva e silenciosa. Da mesma forma os processos de construção de si, possibilitados por ela, apresentam muitas possibilidades e nuances em função da época, do lugar

GRUSZYNSKI, Ana Cláudia; MARTINS, Bruno Guimarães; GONÇALVES, Márcio Souza (org.). Edição: agentes e objetos. Belo Horizonte: PPGCOM/ UFMG, 2018.

2. Ibidem, p. 9. 3. Ibidem, p. 17 


\section{comunicação \& educação • Ano XXV • número 2 • jul/dez 2020}

4. Ibidem, p. 27.

5. BURKE, Peter. Uma história social do conhecimento: Il: da Enciclopédia à Wikipédia. Rio de Janeiro: Zahar, 2012.

6. DARNTON, Robert. The case for the books: past, present, and future. New York: Public Affairs, 2009.

7. JACOBS, Alan. The pleasures of reading in an age of distraction. New York: Oxford University Press, 2011.

8. GRUSZYNSKI; MARTINS; GONÇALVES. Op. cit., 2018. p. 37.

9. Ibidem, p. 52

10. SANTAELLA, Lúcia. Corpo e comunicação: sintoma da cultura. São Paulo: Paulus, 2004

11. GIBSON, 1996, p. 4 apud SANTAELLA, 2004, p. 38.

12. MARTINO, Luís Mauro Sá. Comunicação e identidade: quem você pensa que é? São Paulo: Paulus, 2010.

13. ONIANS, John. Neuroarthistory: from Aristotle and Pliny to Baxandall and Zeki. Londres: Yale University Press, 2008. e do grupo em questão. O leitor tem um papel fundamental na leitura, como afirmam diferentes estudiosos do tema. Um texto só se completa com o leitor. É ele, com seu horizonte de expectativas, para usar um termo de Jauss (1996), que dará sentido ao texto. Um sentido que expressa a relação entre o próprio texto e o contexto do leitor. Uma dimensão de apropriação e de subjetivação. As duas pesquisas apresentadas brevemente neste trabalho demonstram a importância do romance como gênero privilegiado para os leitores contemporâneos, sejam eles do Ceará ou da França $a^{4}$.

No segundo artigo, Uma aventura de leitores no país metafórico dos livros, André Carlos Moraes faz uso da metáfora "território" para vislumbrar o papel do leitor ao se embrenhar por regiões a serem exploradas. A metáfora "aventura" também é lançada para apresentar resultados de uma pesquisa de seis anos com estudantes universitários. Moraes faz uso de autores como Burke $(2012)^{5}$, Darnton $(2009)^{6}$ e Jacobs $(2011)^{7}$ e da analogia geográfica, quase cartográfica, para definir territórios de leitores - sejam eles territórios físicos ou espaços de integração, de comunidades que se identificam com determinados gêneros. Metáforas territoriais e fronteiriças trazidas por Moraes, são, "chaves interpretativas para os dados observacionais" propostos no artigo. A pesquisa apresenta:

[...] um levantamento com estudantes universitários de primeiro ano da Universidade Federal do Rio Grande do Sul (UFRGS), realizado em três etapas, em 2011, 2014 e 2016. Os alunos responderam a um questionário fechado autopreenchido que perguntava sobre táticas de estudo e hábitos pessoais de leitura. Participaram estudantes de Medicina, Direito, Psicologia, Publicidade e Propaganda, Jornalismo, Relações Públicas, Letras, Biologia, Ciência da Computação, Engenharia Civil e Veterinária. Foram 667 participantes que responderam ao formulário em sala de aula, dos quais 31 também foram entrevistados posteriormente por telefone. Entre os objetivos do trabalho estava a observação das escolhas de plataforma de estudo ou leitura por parte dos estudantes. Buscava-se compreender em um contexto empírico como o livro tradicional convive, no contexto informacional dos jovens, com outros meios de comunicação e suportes de conteúdo ${ }^{8}$.

Em A leitura vem de dentro: sentidos no ato de ler em diferentes dispositivos, Marília de Araujo Barcellos propõe logo de início o questionamento: "sendo o livro uma mídia que permite o registro do conhecimento [...], o quanto de desafio há em tempos de compartilhamento intenso e de múltiplos suportes e materialidades?" ${ }^{9}$. Está no foco da investigadora refletir como se dá a apreensão de conteúdos em contextos multiplataformas e como se dão sinapses mentais diante de suportes distintos. A autora dialoga com Santaella ${ }^{10}$ e sua análise da obra de Gibson $^{11}$. Integra ainda a visão de Martino ${ }^{12}$, relacionando terminações nervosas ao processo cognitivo e ao processo de recepção da leitura. Martino cita Onians ${ }^{13}$ em seu entendimento da relação entre atividades cerebrais e modos de recepção.

O texto de Barcellos realiza uma importante análise das atuações do mercado em relação a possibilidades de produção e consumo, bem como à 
coexistência de material impresso e digital, destacando o espaço conquistado pela autopublicação. "Com a ampliação das plataformas de publicação, o papel dos agentes formadores do campo [...] sobrepõe-se em camadas que não mais delimitam o tempo e o espaço. Alastram-se entre línguas, países e formatos" ${ }^{14}$.

Já no capítulo Era uma vez um Correio Infantil: o protagonismo do leitor na página das crianças do Correio do Povo (Porto Alegre, RS, 1958-1984), Cida Golin debruça-se sobre o suplemento infantil como produto de leitura e, igualmente, promotor de livros e do processo leitor por parte de crianças, considerando o papel educativo e a relação entre leitura na escola e para a escola e a leitura recreativa.

Inaugurando a parte Materialidades e produção de sentidos, Gonçalves, Barbosa e Silva indagam: "a materialidade dos tempos importa?" ${ }^{5}$. No texto Mapeando sentidos: texto, materialidade e leitura, os autores averiguam objetos comunicacionais, suas características, modos de usos, apropriações e sentidos, além da relação entre a leitura e as propostas tecnológicas atuais e redes de relações sociais. Ao abordar o audiolivro, sua linearidade e materialidade, observa-se o quanto a invisibilidade desse produto pode velar a hibridização de sentidos (visão e audição).

Em Harry Potter: do impresso às enhanced editions, Sanseverino parte do sucesso editorial infantojuvenil internacional e analisa seu espraiamento para outras mídias e materialidades, bem como a hibridização e presença de mídias anteriores nas propostas recentes (caso do livro digital e dos enhanced editions, obras digitais com recursos audiovisuais e efeitos diversos). Na análise, traz nas distintas formas de apresentação da série editorial não apenas um recurso mercadológico, mas também outras possibilidades de leitura e imersão na história.

As maneiras de se ler jornal e de se fazer o jornal, incluindo recursos de projeto gráfico, são averiguadas por Hoewell, Damasceno e Gruszynski em As formas do (ciber)jornal. "No caso dos jornais, há de se considerar as características que compõem a natureza do produto para compreender as alterações na materialidade, tendo em vista que meios, materiais e circunstâncias de leitura produzem sentido, transformando as relações de tempo e espaço" ${ }^{\text {. }}$.

O projeto visual de revistas é fio condutor do próximo artigo, Re/vis-à-vis/ tas serrote e WTW: uma incursão sociocultural no design gráfico editorial, articulado por Vaz e Belo. Os autores analisam as revistas Serrote, do Instituto Moreira Salles, e a holandesa Works That Work (WTW), tendo no desenho gráfico o foco da experiência leitora.

No conjunto de artigos destinados às editoras e edição, temos o primeiro deles abordando a obra bilíngue. Bruchard inicia sua análise com a observação de que toda tradução é um movimento em direção ao leitor e a busca por um diálogo entre uma linguagem e uma outra cultura com a língua e cultura dos leitores. O texto traz um resumo sobre a história de obras bilíngues e aborda as traduções infantojuvenis, dando especial atenção aos clássicos internacionais, bem como traduções de obras da cultura indígena brasileira. Para Bruchard, um destaque das obras bilingues reside na percepção da alteridade.

14. GRUSZYNSKI MARTINS; GONÇALVES Op. cit., 2018. p. 69

15. Ibidem, p. 101. 16. Ibidem, p. 115. 
comunicação \& educação • Ano XXV • número 2 • jul/dez 2020

Quando acolhe, em pé de igualdade, duas linguagens-culturas que tudo tende a separar e distanciar, o livro bilíngue promove, mais que nada, uma nova percepção sobre seus usuários. E quando, na leitura partilhada, permite que se acolham mutuamente as diferenças, revela-se um meio privilegiado de inclusão social. Portador de alteridade, educa o olhar para um mundo plural e diverso ${ }^{17}$.

Dentre as estratégias atuais dos produtores de livros estão as ações de editoras independentes, analisadas por Muniz Jr. em Sagração da Primavera: formação de conglomerados e coletivização da independência. $\mathrm{O}$ artigo dá centralidade à Casa da Palavra e à atuação de seu editor na criação da Libre (Liga Brasileira de Editoras). Discute ainda a presença de grandes grupos editoriais internacionais no mercado brasileiro, caso do conglomerado português LeYa e da Penguin/Random House, que adquiriram uma porcentagem da Editora Companhia das Letras.

Estratégias mercadológicas são focadas em Marketing de conteúdo: a busca das editoras brasileiras em aproximar e conquistar leitores. Oliveira averigua o relacionamento de editoras nas redes sociais, bem como os conteúdos criados como estratégia para aproximar leitores. A relevância de mulheres editoras é abordada por Ribeiro em Mulheres editoras de livros (literários): por um mapeamento preliminar no Brasil. O artigo traz dados de uma pesquisa, revelando como se dá a participação dessas mulheres na atualidade, bem como nível de profissionalização e tipos de produtos editoriais. Chama atenção igualmente para a necessidade de se recuperar trajetórias de figuras femininas de destaque no mercado brasileiro.

A coletânea de artigos encerra com cinco textos abordando expressivas iniciativas editoriais ao longo da história brasileira. No primeiro deles, Guimarães analisa a atuação da Gráfica de Artes S.A., oficina artesanal que durante os anos de 1942 a 1969 serviu um grupo denominado Sociedade dos Cem Bibliófilos do Brasil.

Em A figuração do circuito editorial no movimento romântico brasileiro, Bertol reconstrói os caminhos trilhados para a chegada do romantismo ao nosso país, numa trilha que parte da Alemanha mas tem passagens pela França. Já Reimão empreende importante análise sobre a censura de obras durante a ditadura miliar no Brasil (1964-1985). Seu foco nesse artigo está em obras portuguesas que deixaram de circular em território brasileiro por atuação da censura de produtos culturais. Merece destaque a atuação de intelectuais portugueses exilados no Brasil, contribuintes para a formação do que Antonio Candido denomina missão portuguesa ${ }^{18}$.

Calza investiga as obras de costume, publicadas entre os séculos XVI e XVII

17. Ibidem, p. 207.

18. CANDIDO, Antonio. O albatroz e o chinês. Rio de Janeiro: Ouro sobre Azul, 2004.

19. GRUSZYNSKI; MARTINS; GONÇALVES. Op. cit., 2018. p. 337.

20. Ibidem, p. 386. e responsáveis "pela difusão das roupas, dos acessórios e da moda"19. Sua análise se volta especialmente ao projeto gráfico dos livros, com detalhamentos sobre tipografia. Tipografia é também o elemento central do artigo final, elaborado por Martins e denominado Modulações tipográficas: o oral e o manuscrito na Gazeta dos Tribunais (1843-1846). Neste texto, Martins propõe um contraponto entre a rigidez do discurso jurídico com a "desordem de sua experiência cotidiana" ${ }^{20}$ presente na oralidade. 
Edição: agentes e objetos é documento relevante sobre as investigações do universo editorial do passado e da atualidade. Nas escritas e modos de fazer e de consumir livros, jornais, revistas, sites e produtos analógicos e digitais, estão inscritos trechos da história editorial brasileira. Há ainda informaões e reflexões de grande importância para entender processos comunicacionais e educacionais do fazer editorial e do ser leitor no Brasil.

\section{REFERÊNCIAS BIBLIOGRÁFICAS}

BURKE, Peter. Uma história social do conhecimento: II: da Enciclopédia à Wikipédia. Rio de Janeiro: Zahar, 2012.

CANDIDO, Antonio. O albatroz e o chinês. Rio de Janeiro: Ouro sobre Azul, 2004.

DARNTON, Robert. The case for the books: past, present and future. New York: Public Affairs, 2009.

GRUSZYNSKI, Ana Cláudia; MARTINS, Bruno Guimarães; GONÇALVES, Márcio Souza (org.). Edição: agentes e objetos. Belo Horizonte: PPGCOM/ UFMG, 2018.

JACOBS, Alan. The pleasures of reading in an age of distraction. New York: Oxford University Press, 2011.

MARTINO, Luís Mauro Sá. Comunicação e identidade: quem você pensa que é? São Paulo: Paulus, 2010.

ONIANS, John. Neuroarthistory: from Aristotle and Pliny to Baxandall and Zeki. Londres: Yale University Press, 2008

SANTAELLA, Lúcia. Corpo e comunicação: sintoma da cultura. São Paulo: Paulus, 2004. 